\title{
CUBA Y SU FUTURO. ALGUNAS REFLEXIONES SOBRE MATERIA CONSTITUCIONAL*
}

\begin{abstract}
RESUMEN: En Cuba habrá que elaborar una nueva Constitución; corta y sencilla, sin caer en la minuciosidad y en el casuismo. Deberá estar a cargo de especialistas en la materia y sometida a referendo. A la sección dogmática y orgánica deberán sumarse las disposiciones en materia de organización territorial del Estado, política económica y hacienda pública, además del sistema de reforma de la Constitución. El resto del marco jurídico deberá dejarse a la legislación secundaria. Para ello, habrá que modificar, revocar y sustituir leyes autoritarias y represivas actuales, como el Código Penal; habrá que promulgar otras que se adapten a la nueva carta magna, como una nueva Ley Orgánica del Poder Judicial y una Ley Electoral cuyo marco legal garantice la realización de elecciones libres, imparciales, justas y equitativas que garanticen un porvenir de democracia y Estado de derecho para la Isla.
\end{abstract}

Palabras clave: Cuba, Constitución, democracia, elecciones, legislación, referendo.

\section{Beatriz BERNAL**}

ABSTRACT: In Cuba will require developing a new Constitution; short and simple, without falling in details and casuistry. Its development should be carried out by specialists and subjected to a referendum. Besides dogmatic and organizational sections there must be provisions in terms of territorial organization of the State, economic policy and public finance, and a system to amend the Constitution. The rest of the legal framework should be left to secondary legislation. Change, repeal and replace the current repressive and authoritarian laws is required, such as the Penal Code; it will have enact others according to the new Magna Carta, as a new organic law of the Judiciary and Electoral Act under which legal framework guarantees the realization of free, fair, just and equitable elections to ensure a future of democracy and rule of law for the island.

Descriptors: Cuba, Constitution, Democracy, Elections, Legislation, Referendum.

\footnotetext{
* La primera versión fue publicada con el título de "Ideas constitucionales para una Cuba futura”, en Democracia, desarrollo y sociedad civil en Cuba (Cádiz, 2004), y en Memorias del I Congreso Internacional de Cultura Cubana (Asociación Española Cuba en Transición, 2004). Ahora se amplía y pone al día con los nuevos acontecimientos que han afectado el ámbito político cubano en los tres últimos años y sehacen propuestas constitucionales, institucionales y legislativas para lograr el Estado de derecho en la Cuba futura.

** Investigadora en el Instituto de Investigaciones Jurídicas de la UNAM.
}

Fecha de recepción: 10 de abril de 2008.

Fecha de dictamen: 2 de julio de 2008. 
No hay duda de que los países más desarrollados del mundo han tenido históricamente y tienen en la actualidad como opción política la democracia y como opción jurídica el Estado de derecho. O dicho en otras palabras: "Hay hoy en día una creencia ampliamente extendida de que la existencia del Estado de derecho, acompañado de la democracia y la libertad política son necesarios para el crecimiento y la prosperidad económica". A estos dos conceptos, democracia y Estado de derecho, así como a los cambios constitucionales y legislativos encaminados a lograr el desarrollo político que la Cuba postotalitaria necesita y se merece, dedico estas reflexiones.

En este orden de ideas las preguntas que me planteo son las siguientes: 1) ¿hay en Cuba una Constitución que garantice el Estado de derecho en el futuro?; 2) ¿puede llevarse a cabo la transición a la democracia apelando a la Constitución de 1940 o a la de 1976-1992, actualmente vigente?;2 3) ¿qué hacer, desde un punto de vista constitucional para garantizar en el futuro dicho Estado de derecho?

Antes de continuar, una salvedad. Mis reflexiones se refieren solamente a los cambios en el ámbito del derecho, esto es, a cómo debería ser la armazón jurídico-institucional de la Cuba futura. Digo esto porque estoy consciente de que para que se lleven a cabo estos cambios que propongo se requiere previamente de un "pacto político" que desemboque en el establecimiento de las condiciones necesarias para un rediseño del modelo de Estado. ¿Se llevará a cabo algún día dicho "pacto político"? ¿Cuándo? ¿Cómo y entre quienes? No tengo la respuesta. No soy politóloga, y tampoco adivina. Menos en este momento en que la renuncia a presidir el Consejo de Estado de quien ha detentado el poder omnímodo en Cuba durante casi 50 años, Fidel Castro, no parece encaminarse a cambio constitucional alguno. Pienso así porque, a pesar de las expectativas de un buen número de cubanos de dentro y fuera de la isla, en el sentido de una sustitución del Comandante por algún miembro reformista de su régimen, la decisión que tomó la Asamblea Nacional del Poder Popu-

1 Véase Patallo, Laura, Establecimiento del Estado de derecho en Cuba, Cuba Transition Proyect, University of Miami, 2003.

2 Me refiero a esta Constitución utilizando las dos fechas debido a que considero que, aunque varios constitucionalistas, en especial los que viven en la isla, la denominan Constitución de 1992, es realmente la de 1976 reformada. Una reforma profunda, es cierto, resultado de la crisis económica que sufrió el país con la caída del comunismo, pero reforma al fin. 
lar el 24 de febrero de 2008, tres días después de la renuncia de Castro, fue nombrar a su hermano menor, Raúl, como nuevo presidente del Consejo de Estado, así como a varios vicepresidentes y un secretario general, pertenecientes, casi todos, a la vieja guardia del movimiento revolucionario que triunfó en 1959. Sólo puedo adelantar que vislumbro que en dicho "pacto político", cuando se dé, intervendrán desde los reformistas agazapados en el actual gobierno cubano hasta los bravos disidentes que desde hace un par de décadas, y cada vez con mayor frecuencia e intensidad, proponen reformas políticas y económicas al actual modelo de Estado. Y también los grupos políticos que se han organizado en el exilio y que, desde hace mucho tiempo, trabajan sobre posibles escenarios y diseños de transición. Sin olvidar, por último, a países de la comunidad internacional que por distintas razones, ya sean éstas políticas, económicas o migratorias, intentarán influir en el futuro de Cuba.

Vuelvo ahora al tema que especialmente me ocupa.

Una Constitución, dentro de nuestra tradición jurídica occidental y, por tal razón, dentro de la tradición que imperó en Cuba durante la primera mitad del siglo pasado, es la carta magna que garantiza la democracia y que regula lo que llamamos Estado de derecho. Esto es, un Estado donde las leyes sustituyan al uso arbitrario del poder y donde todas las personas sean iguales ante la ley y estén sujetas a ella. Y a este Estado, ya sea liberal o social, le son necesarios los siguientes requisitos:

1. El imperio de la ley como expresión de la voluntad popular. Dicho en otras palabras, "el gobierno de las leyes y no "el gobierno de los hombres". Esto es, el poder sometido a la norma jurídica, que es lo que garantiza a los ciudadanos los principios de libertad, de igualdad y de justicia y que, además, les otorga ese bien indispensable para la consecución de dichos principios: la "seguridad jurídica", bien éste que, asimismo, garantiza la correcta interpretación y aplicación de las leyes.

2. La legalidad de los actos de administración y su control judicial, así como la constitucionalidad de las normas secundarias o derivadas de la norma máxima en la jerarquía de las leyes: la Constitución.

3. La división de los poderes Ejecutivo, Legislativo y Judicial, a la manera clásica, con su consecuente equilibrio y control entre ellos, así como la autonomía del Poder Judicial que interpretará y aplicará la norma jurídica con absoluta independencia de los otros dos poderes, $\mathrm{y}$, 
4. La garantía jurídica de los derechos y libertades fundamentales, que no es más que la garantía de la libertad y de la igualdad de todos los hombres ante la ley.

¿Se cumplen estos requisitos en la Constitución actualmente vigente? En mis recientes trabajos: "Cuba ¿Estado de derecho", ${ }^{3}$ Las Constituciones de Cuba republicana ${ }^{4}$ y Constituciones Iberoamericanas. Cuba, ${ }^{5}$ creo haber demostrado lo contrario. "Hoy Cuba — como bien dice Laura Patallo-, no funciona ni siquiera bajo la definición más flexible de Estado de derecho" ¿Por qué? Y esto lo digo yo, porque en la Cuba actual no impera la ley como expresión de la voluntad popular, ni hay control judicial de los actos de la administración, como tampoco garantía de la constitucionalidad como tampoco de las leyes, ni división de poderes con su consecuente equilibrio entre ellos. Por el contrario, el Estado cubano está estructurado bajo el principio de "Unidad de poder", esto es, un solo poder con división de funciones, al estilo de las Constituciones de los países totalitarios. Ni, por supuesto, hay independencia del Poder Judicial. Tampoco existe una garantía jurídica de los derechos y libertades fundamentales que son frecuentemente conculcados.

Y lo que es peor, Cuba no cuenta con una cultura de Estado de derecho. No quiere esto decir que en Cuba no haya leyes, las hay y muchas; leyes, dicho sea de paso, que con frecuencia se cambian sin previo aviso, pero el gobierno de la isla no está constreñido, y los cubanos, pienso, tras casi 50 años de intervencionismo estatal, no creen en la supremacía de la ley máxima y mucho menos de las derivadas, aunque no se me oculta la influencia que haya dejado en ellos el adoctrinamiento marxista. En resumen, no hay que ser un experto en leyes para afirmar que, sin una aceptación muy extendida de esta creencia, un Estado de derecho no puede sostenerse. Tampoco para pronosticar que la transición hacia la democracia y hacia la creación del Estado de derecho será una labor ardua y muy lenta, aunque, más temprano que tarde, haya que avocarse a ella. ${ }^{7}$

3 Véase Bernal, B., Cuba y sus leyes. Estudios histórico-jurídicos, México, UNAM, 2002, pp. 165-172.

4 Miami, Instituto y Biblioteca de la Libertad, 2003, pp. 37-48.

5 México, UNAM, Instituto de Investigaciones Jurídicas, 2008.

6 Op. cit., nota 1, p. 5.

7 En igual sentido, Patallo, Laura, op. cit., nota 1, p. iiii. 
Dicho lo anterior, añado que, para que Cuba cuente con una Constitución que sea el verdadero instrumento de la modernización política que la isla necesita; esto es, la "expresión resumida de una sociedad igualitaria, dinámica, democrática, cientifista y económicamente desarrollada", según palabras de Miguel Herrero y Rodríguez de Miñón, ${ }^{8}$ uno de los padres de la Constitución Española de 1978, será indispensable, en su momento, integrar unas cortes constituyentes donde, debidamente representadas las fuerzas políticas y sociales del país, se promulgue una nueva Constitución que garantice el Estado de derecho.

Sin embargo, para que esto suceda, se requiere un periodo de transición entre el fin del régimen totalitario y el de la integración de las Cortes constituyentes. Durante ese periodo, el país seguirá funcionando y deberán mantenerse los servicios públicos, las relaciones sociales y comerciales $\mathrm{y}$, hasta cierto punto, la administración de justicia. ¿Puede eso lograrse sin el marco jurídico de una carta magna? Yo creo que no.

Entonces, la alternativa está entre volver a la mítica Constitución de 1940, no abrogada formalmente o mantener en vigor la Constitución de 1976-1992, debidamente reformada o enmendada hasta que llegue el momento de las nuevas cortes constituyentes. Entre los partidarios de la primera alternativa hay destacados constitucionalistas residentes, tanto en Miami como en Cuba, así como grupos de disidentes en la isla. ${ }^{9}$ Yo,

8 Véase Herrero y Rodríguez de Miñón, "Modelos de transición del autoritarismo a la democracia. Ideas para Cuba", Ideas jurídicas para la Cuba futura, Madrid, Fundación Liberal José Martí, 1993, p. 81.

9 Por ejemplo, en tal sentido se expresan el constitucionalista Néstor Carbonell y otros, desde Miami y el presbítero Carlos Manuel de Céspedes, desde Cuba, en varios escritos al respecto. Véase de Carbonell los artículos: "La Constitución de 1949: simbolismo y vigencia", ASCE, 1997; "Redescubrimiento de la Constitución" publicado en El Nuevo Herald el 8 de septiembre de 2002, y “¿Reformismo o Liberación?”, publicado en Diario de las Américas en diciembre de 2003; así como "Y sin embargo pervive" (http://futurodecuba.org); artículo este último en respuesta a las críticas que hace el economista Jorge A. Sanguinetty a la Constitución de 1940 en: "El fetiche de la Constitución del 40", publicado en El Nuevo Herald, el 3 de octubre de 2001; véase Rubén A. Ricardo, "Legalidad y vigencia de la Constitución cubana de 1940", Diario de las Américas, 18 de agosto de 2002; véase de Céspedes el ensayo, "Aproximación a la Constitución de 1940”, Encuentro de la cultura cubana, Madrid, núm. 24, primavera de 2002. Asimismo, a mediados del pasado año, un grupo de disidentes cubanos, liderado por René Gómez Manzano, Bonne Carcassés y Elsa Morejón elaboraron un documento que han puesto a la firma de los cubanos que deseen apoyarlo donde, además de pedir una amnistía general 
sin embargo, coincidiendo en ello con el punto de vista de otros disidentes cubanos, ${ }^{10}$ propongo lo segundo con base en el capítulo $\mathrm{XV}$, artículo 137 de la Constitución actual que prevé su reforma total o parcial a través del voto de las dos terceras partes de los miembros de la Asamblea Nacional del Poder Popular, seguido por un referendo ciudadano que lo ratifique, convocado al efecto por la propia Asamblea.

¿Cuáles son mis razones? Primera, que la historia nunca vuelve atrás y quien pretenda hacerlo se estrella contra sus leyes; segunda, que es con la Constitución en vigor con la que están, hasta cierto punto, familiarizados los cubanos de la isla hace más de un cuarto de siglo; mientras que, casi siete décadas después, la Constitución de 1940 ha desaparecido de su memoria colectiva, aunque reconozco que no ha sido así entre quienes nos formamos como juristas en los viejos tiempos de la tan denostada República anteriores a la revolución, y algunos disidentes actuales en Cuba; y tercera, que para asegurar una transición pacífica en la isla, que es lo que queremos casi todos los cubanos, bastaría, en el ámbito constitucional, además de la apertura de un proceso de revisión sin quiebra de la legalidad existente, con cumplir los siguientes requisitos: a) una reforma del capítulo XIV (artículos 131-136) de la Constitución dedicado al

para los presos de conciencia y un régimen económico de mercado libre, solicitan una transición pacífica con base en la reinstalación de la Constitución de 1940. Dicho documento se basa y coincide con los escritos elaborados por los también disidentes, así como larga y frecuentemente encarcelados Oscar Elías Biscet y Martha Beatriz Roque. Una posición intermedia es la que sustenta Alberto Luzárraga, constitucionalista cubano en Estados Unidos quien hace dos propuestas. La primera consiste en dictar por decreto una ley fundamental de carácter transitorio. (Véase Lúzárraga, "Constitución Cubana: Reflexiones sobre el futuro. II Parte. Los objetivos generales", http.www.://futurodecuba.org, 30 de mayo de 2002). La segunda, posterior en el tiempo, propone un retoque realizado por una comisión de juristas, a una de las dos Constituciones aprobadas en Cuba por asambleas constituyentes (las de 1901 y 1940), sujeto a aprobación por un Senado previa y debidamente electo y luego por un referéndum. (Véase Luzárraga, "¿Qué debe incluir una Constitución? Cambio, Constitución y sentido común", http://www.futurodecuba.org, de 2007).

10 En tal sentido se ha expresado, en múltiples comunicados, Osvaldo Payá, líder del Movimiento Cristiano de Liberación y premio Sajarov 2002. Payá basó en reformas a la Constitución 1976-1992 su ya famoso "Proyecto Varela" de 21 de mayo de 2001 (véase http://www.contactomagazine.com, 24, 3, 2002), y presentó, el 10 de mayo de 2006, un proyecto para modificar la actual Constitución, bajo el título de "Propuesta de Constitución de la República de Cuba" en el "Programa Todos Cubanos" (Véase http://www.lanuevacuba.com, 1, 9, 2006). 
sistema electoral que incluya el pluripartidismo; b) la celebración de unas elecciones democráticas a la Asamblea Nacional basadas en la nueva Ley Electoral y c) la formación de un nuevo gobierno capaz de dirigir el proceso de revisión constitucional diseñado en el artículo 137, antes mencionado. ${ }^{11}$

Además de lo dicho relativo a la reforma del sistema electoral, ¿cuáles serían los otros cambios necesarios para que la Constitución actualmente vigente sirviera para un proceso de transición? El politólogo e historiador Jorge I. Domínguez en su estudio: "Una Constitución para la transición política en Cuba. La utilidad de retener (y enmendar) la Constitución de 1992", 12 opina que habría que desmantelar su triada de instituciones autoritarias. A saber: 1) el monopolio del Partido Comunista; 2) la militarización de la sociedad y, 3) las estructuras de mando sobre la economía y la sociedad. Asimismo, el texto constitucional también debe perder su lenguaje doctrinario marxista-leninista y debe ser derogada la Ley de Reforma Constitucional de junio de 2002, que se promulgó como reacción al "Proyecto Varela", promovido por el disidente Osvaldo Payá en 2001, y que declaró "irrevocable" el sistema político, económico y social establecido en la Constitución, prohibiendo así cualquier enmienda futura al texto básico.

Empecemos por el lenguaje doctrinario. Este lenguaje, típico de las ya desfasadas dictaduras comunistas y que alude al internacionalismo proletario, a la explotación capitalista del hombre por el hombre, a la unidad de los países del Tercer Mundo, a la lucha contra el imperialismo, el fascismo y el colonialismo, permea toda la Constitución. Está presente, no sólo en el Preámbulo, que debe ser reducido drásticamente, sino también en gran parte de los artículos (10., 4o., 5o., 6o., 7o., 9o., 10, 12, 13, 14, $30,38,39,43,45,53,54,62,64$ y 68) de la sección dogmática de la Constitución que deben ser reformados. Opino que el pueblo cubano, aunque familiarizado con dicho lenguaje, está harto de oírlo, y que en un proceso de transición agradecerá que lo supriman de su carta magna porque imponen una visión de Cuba desde el gobierno al resto de la sociedad.

11 Véase Herrero y Rodríguez de Miñón, op. cit., nota 9, p. 102.

12 Véase Domínguez, Jorge I., A Constitution for Cuba's Political Transition: The Utility of Retainin (and Amending) the 1992 Constitutio, Institute for Cuban and Cuban-American Studies, University of Miami, 2003. 
Con respecto al monopolio del Partido Comunista, habría que suprimir los artículos 5o., 6o. y 7o., que estipulan, el primero, la supremacía del mismo como "vanguardia organizada de la nación cubana" y "fuerza dirigente superior de la sociedad y el Estado" con los "altos fines de la construcción del socialismo y avance de la sociedad comunista"; que da rango constitucional, el segundo, a la Unión de Jóvenes Comunistas (UJC) como cantera de formación de futuros ciudadanos ideologizados en la tradición marxista-leninista; y que estimula, el tercero, a las organizaciones de masas y sociales "con fines de consolidación y defensa de la sociedad socialista". Dichos artículos, acordes con las reformas que se hagan al capítulo relativo al "sistema electoral", podrían ser redactados de nuevo promoviendo la organización de partidos y asociaciones políticas libres, y estimulado las organizaciones de la sociedad civil. También habría que suprimir el inciso c) del artículo 39 que promueve la educación comunista de las nuevas generaciones; así como modificar el inciso i) que da supremacía a las organizaciones de masas y sociales en la realización de la política educacional y cultural del país. En igual sentido habría que suprimir en el artículo 40 la referencia a las organizaciones de masas y sociales como impulsoras "de la formación integral de la niñez y la juventud". Otro tanto ocurre con el tercer párrafo del artículo 45, referente al trabajo voluntario, donde habría que suprimir su objetivo de "formar la conciencia comunista de nuestro pueblo". Es más, y con vistas a una buena técnica legislativa, en cada una de las referencias en que aparecen las organizaciones de masas y sociales (artículos 50, 68, 88 y otros), podrían éstas ser sustituidas por una alusión general a la sociedad civil.

La militarización de la sociedad es un hecho en la Cuba actual, tanto en sus implicaciones económicas como políticas. No olvidemos que durante décadas el castrismo ha estado en pie de guerra esperando una supuesta invasión de los Estados Unidos de Norteamérica. Esto queda claro en los artículos 101 y 119 que crean los organismo dedicados a la defensa nacional, así como a las provinciales, municipales y regionales para que, desde tiempo de paz y partiendo de un plan general de defensa que depende del Consejo de Defensa Nacional, se preparen para la guerra y los estados de emergencia. Estos dos artículos deben ser suprimidos. También el artículo 65 que establece el servicio militar obligatorio. La Cuba futura necesitará, como todo Estado democrático, de una efectiva y 
profesional policía de tierra, mar y aire (incluyendo la guardia costera, pero no de una fuerza militar como la que tiene ahora, la más grande de América Latina, aunque no tengo elementos para compararla con la de la actual República Bolivariana de Venezuela. Mantener esta fuerza militar en Cuba representa un gasto demasiado gravoso para el Estado y no se corresponde con el tamaño y demografía de la isla, independientemente del control excesivo a que somete a la población civil. Por último, habría que suprimir, por razones obvias, el artículo 134 que otorga a los miembros de las Fuerzas Armadas el derecho a ser elegidos para cargos públicos, así como, de las pocas referencias que se hacen a éstas, el apellido de Revolucionarias.

La centralización de la economía y la sociedad impregna gran parte de la Constitución. El artículo 9o., que corresponde al capítulo I dedicado a los "Fundamentos políticos, sociales y económicos del Estado", establece el control absoluto del Estado en estos tres aspectos. Los artículos, del 14 al 26 regulan la propiedad estatal, los fundamentos de la economía centralizada y planificada y las limitaciones a la propiedad privada (personal y campesina). Todos ellos deben que ser reformados con el fin de proteger dicha propiedad, indispensable para lograr el crecimiento económico de Cuba. Una nueva redacción del artículo 14 reconociendo el derecho a la propiedad privada resultaría muy conveniente. Domínguez, en su ya citado trabajo, ${ }^{13}$ considera que no será difícil, dado que estima que a partir de los años noventa se comenzó en Cuba la transición económica; transición que quedó plasmada en varios artículos de la Constitución reformada en 1992. Por ejemplo, el artículo 15 abre la puerta a la participación de firmas internacionales en la economía cubana, ${ }^{14}$ derivándola a una ley secundaria; el artículo 17 impone cierta disciplina fiscal a las empresas estatales; ${ }^{15}$ los artículos 19 y 20 amplían los derechos para

13 Ibidem, p. 8.

14 Esto puede deducirse del inciso b) párrafo segundo que dice, refiriéndose a los bienes de propiedad estatal socialista, que son prácticamente todos: "Estos bienes no pueden transmitirse en propiedad a personas naturales o jurídicas, salvo los casos excepcionales en que la transmisión parcial o total de algún objetivo económico se destine a fines del desarrollo del país y no afecten los fundamentos políticos, sociales y económicos del Estado, previa aprobación del Consejo de Ministros o su Comité Ejecutivo".

15 Esto puede deducirse del párrafo segundo que expresa: "Estas empresas y entidades responden de sus obligaciones sólo con sus recursos financieros dentro de las limitaciones establecidas por la ley. El Estado no responde de las obligaciones contraídas por 
la actividad económica privada en régimen de cooperativa y el artículo 25 eleva a rango constitucional el derecho de indemnización por expropiación forzosa. Sin embargo, se trata de medidas muy tibias que requieren de profundas enmiendas en el articulado para lograr el desarrollo económico que se desea. Habría que eliminar, además, todas las referencias a la economía planificada que aparecen en diversas partes de los artículos constitucionales. ${ }^{16}$

Con respecto a los derechos sociales, el "gran avance" en materia de educación y cultura que junto a la salud han constituido la base de la propaganda castrista por casi 50 años, debo decir que éstos tienen también sus obstáculos constitucionales que los convierten en dogmáticos y dirigistas, esto es, carentes de libertad. En torno a ellos, el Estado cubano ejerce un monopolio que está presente a lo largo de la Constitución. En el artículo 9o., eleva a rango constitucional su completa intervención en todos los aspectos de la cultura: la educación, las artes, las ciencias y los deportes, así como en la sanidad y los servicios de asistencia social. También deja explícito su intervencionismo y control en el capítulo $\mathrm{V}$, dedicado a la educación y la cultura (artículos 39 y 40). Estas medidas intervencionistas se eliminarían añadiendo al texto constitucional fragmentos que autorizasen las actividades privadas y de la sociedad civil en cada uno de los acápites dedicados a la educación, la cultura y la asistencia social. La aparición, en la Cuba futura, de organizaciones privadas que, junto al Estado, se encarguen de ellos, debe quedar plasmada, creo, en una Constitución de transición. No hay que olvidar que en nuestra tradición republicana existieron múltiples y muy eficientes organizaciones privadas dedicadas a estos menesteres.

Por otra parte, la sección orgánica de la Constitución, aunque diseñada para concentrar el poder político, o quizás por ello, resulta un vehículo eficiente para canalizar los procesos de rápida transformación que son in-

las empresas, entidades u otras personas jurídicas y éstas tampoco responden de las de aquél".

16 Por ejemplo, las del artículo 75, inciso f) y del artículo 98, inciso b). El primero, que versa sobre las atribuciones de la Asamblea Nacional del Poder Popular, le otorga a ésta la función de: "aprobar los principios del sistema de planificación y de dirección de la economía nacional”. El segundo, sobre las atribuciones del Consejo de Ministros, le otorga a éste la función de: "proponer los proyectos de planes generales de desarrollo económico-social del Estado y, una vez aprobados por la Asamblea Nacional del Poder Popular, organizar, dirigir y controlar su ejecución". 
trínsecos a una transición política del régimen. En efecto, medidas como el carácter soberano y unicameral de la Asamblea Nacional; la ausencia del derecho al veto del presidente del Consejo de Estado, a su vez, presidente de gobierno; la facultad de la Asamblea Nacional de elegir y destituir a los miembros del Consejo de Estado, incluido su presidente; la mayoría simple para la toma de decisiones de la Asamblea Nacional salvo en los casos de reforma constitucional; así como la subordinación de los gobiernos provinciales y municipales al gobierno nacional y del Poder Judicial al Legislativo, y la inexistencia de entidades independientes que tomen decisiones económicas o sociales, agilizarían el proceso. ${ }^{17}$

Como puede observarse, esta sección orgánica contiene elementos útiles para la apertura de un proceso de revisión constitucional que, sin quebrar la legalidad existente, pueda establecer un régimen parlamentario interino favorable a la transición, y a la Constitución que, más temprano que tarde, y quizás bajo el sistema parlamentario, habrá de elaborarse. ${ }^{18}$ No hay que olvidar que las nuevas democracias surgidas después de la caída de los regímenes totalitarios de Europa del Este han seguido la pauta parlamentaria, inspiradas, es cierto, en el ejemplo de las democracias de Europa occidental, pero también facilitadas por la estructura piramidal de las Constituciones comunistas como la de Cuba que tuvieron como referencia la carta magna de la extinta Unión Soviética.

Hasta aquí mi propuesta constitucional para que el país siga funcionando en el periodo de transición. Pero a esta etapa deberá seguir otra, de carácter fundacional, en la cual las diversas corrientes de pensamiento político, agrupadas en partidos, se avocarán a la elaboración de una nueva Constitución (la cuarta en nuestra vida de República independiente aunque sólo la tercera emanada de una Asamblea Constituyente); Constitución que deberá garantizar la democracia y el Estado de derecho en el futuro. Dichas corrientes político-ideológicas representarían tanto a los comunistas y socialistas como a los liberales, conservadores, demócratas cristianos y otros grupos que desde hace décadas, están actuando ya, dentro y fuera del país.

Ahora bien, ¿cómo se haría esta nueva carta magna? La alternativa está entre hacer una convocatoria a una asamblea constituyente por medio de comicios abiertos seguidos de un referendo popular, a la manera

17 Véase Domínguez, op. cit., nota 12, pp. 15 y 16.

18 Véase Herrero y Rodríguez de Miñón, op. cit., nota 8, p. 99. 
tradicional usada en los países occidentales en los dos pasados siglos, o encargar su elaboración a la Asamblea Nacional, constituida previamente a través de elecciones democráticas, después de hecha la reforma a la legislación electoral. Me inclino por la segunda opción, siempre que se constituya una comisión de especialistas en derecho constitucional que tengan a su cargo la elaboración del texto. ${ }^{19}$

La parte dogmática del mismo, quizás la más compleja para lograr un consenso cuando de una asamblea constituyente se trata, deberá ajustarse a los tratados internacionales sobre derechos humanos, ${ }^{20}$ en especial a la ya aprobada Declaración de los Derechos Humanos de la ONU del 10 de diciembre de 1948 (Declaración de San Francisco). Los derechos y garantías individuales, los derechos sociales, los valores como la igualdad y las libertades de pensamiento, expresión, asociación y otras son universales y están ya asentados en las Constituciones de nuestra tradición occidental. Discutir ad infinitum sobre ellos no es más que perder un tiempo precioso que se necesita para la reconstrucción del país.

Ese tiempo, en el ámbito constitucional, debería ser utilizado para asuntos de mayor urgencia y enjundia como la reforma del Poder Judicial, subordinado durante casi medio siglo a los otros dos poderes. Así, siguiendo nuestra tradición desde las Constituciones decimonónicas de "Cuba en armas", ${ }^{21}$ debe elevarse a rango constitucional la independencia del Poder Judicial. Un Poder Judicial honesto, imparcial, independiente y profesional es esencial para establecer y consolidar el Estado de

19 Eso fue lo que hicieron los españoles en la década de los setenta del pasado siglo, lo que dio lugar a la promulgación de la Constitución Española de 1978. Véase de Carlos Alberto Montaner, su artículo, "España o cómo se hace una Constitución”, Firma Press, noviembre 30, 2003.

20 Por ejemplo, el Pacto Internacional de Derechos Económicos, Sociales y Culturales del 16 de diciembre de 1966; la Convención Americana sobre Derechos Humanos de noviembre de 1969 y otros instrumentos internacionales sobre la discriminación por razón racial y de género, la eliminación de la tortura, la desaparición forzada de personas y la violencia contra la mujer.

21 Las de Guáimaro (1869), Jimaguayú (1895) y La Yayá (1897). Véase Bernal, B., "Cuba. Breve historia de sus Constituciones liberales", Ideas jurídicas para la Cuba futura, op. cit., pp. 51-78 y "Las Constituciones liberales cubanas", Ius Fugit, 5-6, Revista Interdisciplinar de Estudios Histórico-Jurídicos, Zaragoza (España), Facultad de Derecho, Universidad de Zaragoza, 1996-1997, pp. 37-52. 
derecho. ${ }^{22}$ Asimismo, debe reinstalarse la carrera judicial y suprimirse los jueces legos instaurados en la Constitución comunista. Siguiendo también nuestra tradición republicana desde la Constitución de 1940, dichos jueces y magistrados deberían acceder a sus cargos mediante concursos-oposición y ser evaluados periódicamente. Para la formación de estos funcionarios sería de suma importancia la creación de una escuela judicial.

Debe reinstaurarse, además, siguiendo los dictados de la Constitución de 1940, un tribunal constitucional que tenga a su cargo velar por la constitucionalidad de los actos de la administración, así como por la de las normas secundarias o derivadas, e instaurarse un consejo nacional del Poder Judicial con el fin de independizar y aislar a la rama jurídica del proceso político. Y debe establecerse de nueva planta la figura del ombudsman o Defensor del Pueblo, quien servirá de árbitro cuando la administración u otros poderes conculquen los derechos de los ciudadanos. Por otra parte, habría que pensar en una mayor autonomía de la Fiscalía General del Estado, actualmente subordinada al Ejecutivo, y establecer sus relaciones con el Defensor del Pueblo, el Ministerio de Justicia, la Suprema Corte de Justicia y el Tribunal Constitucional. ${ }^{23}$

En materia electoral, como ya he dicho, habrá que pensar en una nueva Ley Electoral bajo cuyo marco legal se realicen elecciones imparciales, equitativas, libres y justas, controladas por un Instituto Nacional Electoral y un Tribunal Supremo Electoral (instituciones ambas que serían de nueva creación $)^{24}$ y vigiladas por la comunidad internacional con el fin de garantizar una democracia sin adjetivos.

22 Según el punto núm. 3 del Acuerdo por la Democracia, suscrito en 1998 por una amplia gama de la posición democrática cubana de dentro y fuera de la isla, el gobierno transitorio en Cuba estará obligado a organizar: "un Poder Judicial independiente, imparcial y profesional"; véase Pasos fundamentales para la reconstrucción jurídica de Cuba, Centro de Estudios para una Opción Nacional (CON), julio de 2003.

23 Un trabajo interesante en torno a la reforma del Poder Judicial en la Cuba futura es el de Patallo, Laura, The Role of the Judiciary in the Post-Castro Cuba: Recomendations for Change, Institute for Cuban and Cuban-American Studies, University of Miami, 2003.

24 Ejemplos en América Latina son, en México, el Instituto Federal Electoral (IFE) y el Tribunal Electoral del Poder Judicial de la Federación (TEPJF) que ayudaron en la alternancia para desmantelar el autoritarismo del Partido Revolucionario Institucional (PRI) y, en Venezuela, el Consejo Supremo Electoral, que impidió en 2007, por ahora, la reforma constitucional de Hugo Chávez en el sentido de relegirse indefinidamente como presidente de la República Bolivariana de Venezuela. 
También debería tratarse la conveniencia o no de instaurar un régimen parlamentario. La tradición cubana en tiempos de la República siguió el sistema presidencialista, a la manera del de Estados Unidos de Norteamérica, aunque la Constitución de 1940 instauró un régimen semiparlamentario que nunca se puso en práctica. Igual sucedió en el resto de los países de América Latina salvo en Chile y Brasil en breves periodos de su historia constitucional. ${ }^{25}$ Por el contrario, como ya he dicho, en la mayoría de los países europeos, y en los poscomunistas de la Europa del Este, se ha seguido el sistema parlamentario. Se trata de un asunto muy espinoso que se discute actualmente entre los constitucionalistas de América Latina. Por ejemplo, el autor mexicano Jorge Carpizo, quien acaba de publicar un libro sobre estos temas para nuestro continente, ${ }^{26}$ opina que cambiar por cambiar, rompiendo la tradición presidencialista latinoamericana podría ser contraproducente para sus endebles democracias. Por eso, en su ensayo: “América Latina: ¿cambio de régimen?”, 27 dando múltiples razones, sostiene que el sistema presidencial es tan democrático como cualquier parlamentario e incluso puede contener aspectos más positivos que este último. ${ }^{28}$ Así, propone otorgarle su justo valor al presidencialismo y no atribuirle la totalidad de los fracasos democráticos de la región, pretendiendo que la solución está en la instauración del parlamentarismo. En esta línea de pensamiento se celebró, en el Instituto de Investigaciones Jurídicas (IIJ) de la Universidad Nacional Autónoma de México (UNAM), un importante seminario internacional que reunió a juristas de todo el orbe, con el fin de aportar ideas para el funcionamiento del sistema presidencial, así como coadyuvar a una posible reforma del Estado en México. ${ }^{29}$ Pero en Cuba la situación es diferente al

25 En Chile de 1891 a 1924 y en Brasil de 1961 a 1964.

26 Véase Carpizo, Jorge, Concepto de democracia y sistema de gobierno en América Latina, México, UNAM, 2007.

27 Nexos, México, agosto de 2007, pp. 23-27.

28 Entre estos aspectos positivos que Carpizo llama “fortalezas" están: a) que el elector conoce con mayor precisión por quién está votando para jefe de gobierno; b) que se amplían sus opciones de elección, ya que puede votar por un candidato presidencial de un partido y por congresistas de partidos diversos; c) que hay mayor estabilidad del gobierno debido a que el Ejecutivo y el Legislativo son electos por periodos fijos; y d) que la relativa separación de poderes permite mayor control entre ellos. Ibidem, p. 26.

29 El seminario, organizado por IDEA Internacional y el IIJ de la UNAM, con el auspicio de la Agencia Española de Cooperación Internacional (AECI), se tituló: "Cómo hacer funcionar el sistema presidencial", y duró del 6 al 8 de febrero de 2008. En él inter- 
resto de de los países latinoamericanos. El hecho de que, a partir de la promulgación de la Constitución de 1976, se rompiese en ella la tradición de la familia de los derechos constitucionales de occidente para ser sustituida por la de la familia de los derechos socialistas, abre la puerta para hacer cambios y nuevos señalamientos en esta materia. ${ }^{30}$

Por último, resumo y concluyo con la siguiente reflexión:

En la Cuba futura habrá que elaborar una nueva Constitución que debe ser corta y sencilla, sin caer, como lo hizo la Constitución de 1940, en la minuciosidad y en el casuismo. Su elaboración deberá estar a cargo de especialistas en la materia y sometida a un posterior referendo. En su sección dogmática deberán establecerse solamente los derechos y libertades que el Estado pueda garantizar debidamente. En su sección orgánica deberán perfilarse las instituciones básicas, delinearse los rasgos formales del gobierno y establecerse las normas para la selección de los funcionarios, sean por nombramiento (servicio civil o carrera judicial) o por elección. A ello deberían agregárseles las disposiciones indispensables en materia de organización territorial del Estado, política económica y hacienda pública, y sistema de reforma de la Constitución. El resto del marco jurídico, que requerirá de un esfuerzo previo de revisión de la legislación que la Constitución actual generó, deberá dejarse a la legislación secundaria. Para ello, habrá que modificar, revocar y sustituir las leyes autoritarias y represivas actuales, como el Código Penal, y habrá que

vinieron juristas de México, Estados Unidos, Alemania, Perú, Filipinas, Uruguay, Suecia, Benín, Reino Unido, Australia, Italia, Afganistán, Paraguay, Sudán, Francia, Senegal, Chile, Georgia, Indonesia, Argentina y Brasil.

30 En tal sentido resulta muy interesante y novedosa la propuesta del escritor y político Carlos Alberto Montaner en su artículo: "Razones que aconsejan la creación de un Poder Ejecutivo bicéfalo y un sistema parlamentario proporcional en el poscomunismo cubano", publicado en Ideas Jurídicas para la Cuba futura, Fundación Liberal José Martí, Madrid, 1993. En esta propuesta, además de decantarse por el parlamentarismo, el autor propone la creación de un Poder Ejecutivo con dos cabezas, en el que exista un presidente electo por el voto directo, cuya función no sea la de administrar, sino la de representar a toda la sociedad frente al gobierno y frente a las instituciones del Estado, y un primer ministro, seleccionado por el Parlamento, que se dedique a manejar los caudales públicos de la manera más eficiente. Esto es, un jefe de Estado y un jefe de gobierno que desempeñarían tareas totalmente diferentes pero complementarias. Al jefe de Estado corresponderían dos funciones básicas de la vida pública: la de omsbudsman destinada a defender a los ciudadanos de la maquinaria oficial y la de contralor, destinada a auditar los dineros que emplea la administración pública. Habría que valorar esta propuesta. 
promulgar con celeridad otras muchas que se adapten a la nueva carta magna, por ejemplo una nueva Ley Orgánica del Poder Judicial y una Ley Electoral, bajo cuyo marco legal se garantice la realización de elecciones libres, imparciales, justas y equitativas que garanticen un porvenir de democracia y Estado de derecho para la isla. 